
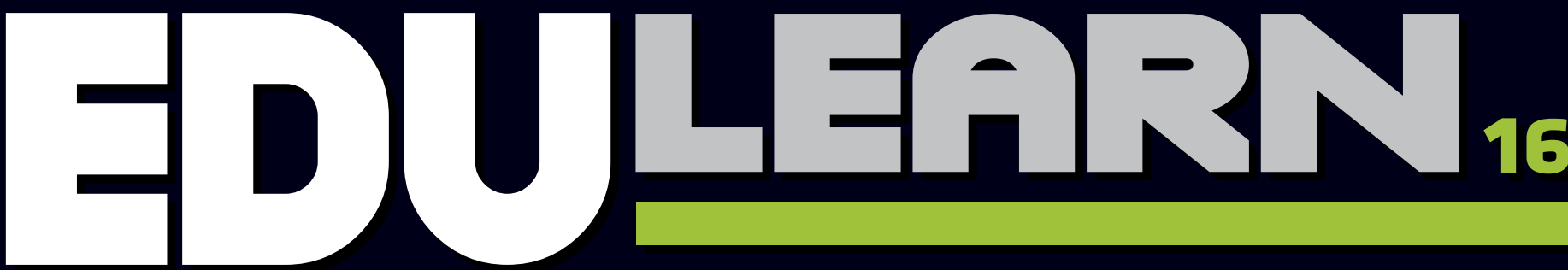

8TH INTERNATIONAL CONFERENCE ON EDUCATION AND NEW LEARNING TECHNOLOGIES 4TH - 6TH OF JULY, 2016
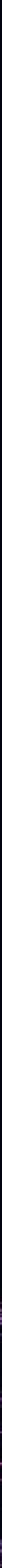
Published by

IATED Academy

iated.org

EDULEARN16 Proceedings

8th International Conference on Education and New Learning Technologies July 4th-6th, 2016 — Barcelona, Spain

\section{Edited by}

L. Gómez Chova, A. López Martínez, I. Candel Torres

IATED Academy

ISBN: 978-84-608-8860-4

ISSN: $2340-1117$

Depósito Legal: V-1421-2016

Book cover designed by

J.L. Bernat

All rights reserved. Copyright () 2016, IATED

The papers published in these proceedings reflect the views only of the authors. The publisher cannot be held responsible for the validity or use of the information therein contained. 


\title{
ONLINE TEACHING IN CONSTRUCTION OF STRUCTURES: PARTICIPATIVE TOOLS
}

\author{
J.C. Pérez-Sánchez, B. Piedecausa-García, V.R. Pérez-Sánchez, R.T. Mora- \\ García, M.F. Céspedes-López
}

Department of Building and Urbanism University of Alicante (SPAIN)

\begin{abstract}
In the last years, traditional teaching has turned around to blended teaching, enabling students and teachers to have a continuous exchange of documentation by using new technologies in the classroom. This kind of teaching is increasingly significant as it combines traditional methods with innovative applications that allow online tracking.

This proposal is applied in the subjects "Construction of Structures I and II" of the Degree in Building Engineering; it implements new methodologies as an alternative to traditional education, strengthening theoretical and practical contents by performing exercises that are corrected in a participatory way using online tools. The aim of this paper is to analyse the use of these tools (such as online tests, participation in forums, virtual tutorials, download of documentation, etc.) in the Moodle platform to encourage interaction and learning. The delivery of online exercises reinforces the acquisition of specific skills and facilitates communication both between teacher-student and between the students themselves.

In conclusion, the use of these online tools offered by the Moodle platform has enabled continuous and participatory learning in Construction of Structures; this new proposal is highly valued by students as it allows direct and personalized monitoring by teachers.
\end{abstract}

Keywords: Building Engineering, online, structures, Moodle, construction.

\section{INTRODUCTION}

The subjects Construction of Structures I and II are covered in the curriculum of the Degree in Building Engineering at the Polytechnic School of the University of Alicante. These subjects are also taught at other universities: they may have other names but the same content and skills are covered in them.

Graduates in Building Engineering are considered, among other profiles, specialists in the construction of buildings bearing always in mind the structure as an important part of the constructive process. Therefore, these concepts are taken into account as fundaments for the development of the profession along with other related subjects in the area, being considered the backbone of the Degree in Building Engineering and being directly related to the rest of subjects.

Moreover, it should be noted that the implementation of the new degrees adapted to the structure of ECTS credits proposed by the European Higher Education Area has meant not only a review of the old curriculum of the Degree in Building Engineering, but also an adaptation of new subjects to the needs posed by this new structure. Besides, the advance developed in recent years regarding the use and application of new technologies in learning must be added, which should be incorporated into traditional methodologies by using applications that enable online tracking with a continuous exchange of documentation between students and teachers, facilitating continuous learning.

Thus, the use of online platforms for continuous and participatory learning (with a direct and personalized monitoring by teachers) is proposed, complementing more traditional (both individual and collective) face to face tutorials.

\section{OBJECTIVES}

The aim of this paper is to apply and analyse the use of several tools in the Moodle platform (as virtual tutorials, online tests, download options for complementary materials and documentation, forums, etc.) to encourage interaction and learning by the delivery of online exercises that reinforce the acquisition of specific skills and facilitate communication both between teacher-student and between the students themselves. 
To this end, this proposal is applied in the subjects Construction of Structures I and II of the Degree in Building Engineering during the course $2015-2016$ by introducing new methodologies as an alternative to traditional education, strengthening the theoretical and practical contents by performing exercises which are delivered and corrected in a participatory manner with online tools.

These compulsory subjects are taught in the second year of the Degree in Building Engineering throughout the whole academic year, in the first and second semester respectively. The subjects have 6 ECTS credits taught by the Construction Area of the Building and Town-Planning Department at the University of Alicante, where all kind of building structures are studied using different materials such as concrete, steel and wood among others, acquiring regulatory and constructive necessary knowledge for the professional practice.

The structures used in buildings are studied from the point of view of construction, using different materials and taking into account current regulations, in order to acquire the knowledge and constructive criteria necessary for the future development of the profession. Thus, the specific objectives arisen in the course are:

- Arouse student interest in general construction and in the particular contents of the subject.

- Know constructive systems for the structures of buildings: their constitution, foundations, uses, the way of working and their order, to choose the best option in every situation.

- Learn, analyse and reason the process of execution of each building system, taking into account the behaviour of materials and their way of working, in order to be able to develop and neatly solve the various problems that may appear in future professional practice.

- Understand and apply the existing rules of each constructive system studied.

- Draw the different constructive solutions in a clear, with rigor and orderly manner, by acquiring new knowledge that will allow the student to define and solve problems and construction details related to the construction of structures $[1,2,3,4]$.

During the teaching process, the acquisition of General Transversal Competences (specifically those known as G12: Computer and information skills) is also considered so the use of complementary computer tools has been considered [5, 6, 7]. Thus, during the 2015-2016 academic course new tools within the computing platform Moodle have been used for participation and monitoring of various educational activities in the two subjects. We must say that during this year more than 140 students have been enrolled divided into 4 groups ( 3 are taught in Spanish and 1 is taught in Valencian) where both theoretical and practical online contents have been provided.

\section{MATERIALS AND METHODS}

Program design and course content have been designed taking into account several factors: on the one hand, those determined by regulatory agencies that define 6 ECTS credits for each subject and, on the other hand, those found in the profile of the subjects:

- Construction of Structures I: Overview of concrete and bars, classification and arrangement of reinforcements, shallow foundations, deep foundations, retaining walls, an overview of forged, unidirectional forged, bidirectional forged and application of structural systems.

- Construction of Structures II: an overview of steel construction, types, column bases, supports, beams, metallic structures for covering, metal structure in residential buildings and construction of wooden structures.

Content distribution into thematic blocks allows a continuous program of subjects and the progressive acquisition of skills by practicing the acquired knowledge in theoretical topics. Thus, theory and practice alternate to ensure conceptual learning and its implementation with different objective situations that simulate activities for the development of professional practice.

Both theoretical and practical classes are scheduled so that students know in advance the contents to be taught every day. First, the basics of each subject are exposed in the theoretical classes by using different audio-visual media existing in the classroom. Exposure of class topics will follow the order of the manuals; classroom attendance, daily study of the lesson taught and performing every exercise are fundamental to successfully achieve the objectives. Necessary documentation is progressively published in the Moodle platform prior to the lectures, so that students can study the lesson before being taught by the teacher. 
Later, theoretical knowledge previously acquired is applied in practical classes. The practical statements consist of exercises and construction problems related to structures and they are also progressively published in the Moodle platform according to the schedule of the course and prior to their implementation in class. Constructive solutions proposed are drawn in an orderly, correct and accurate manner; then they are delivered and corrected by the teacher through the Moodle platform, allowing students and teachers to interact.

Finally, in addition to the combination of lectures / practical classes and publishing all the necessary materials online, the methodology is complemented with the support of tools within Moodle platform (Fig. 1) to facilitate practice monitoring and other activities for the proper development and learning of the subjects.

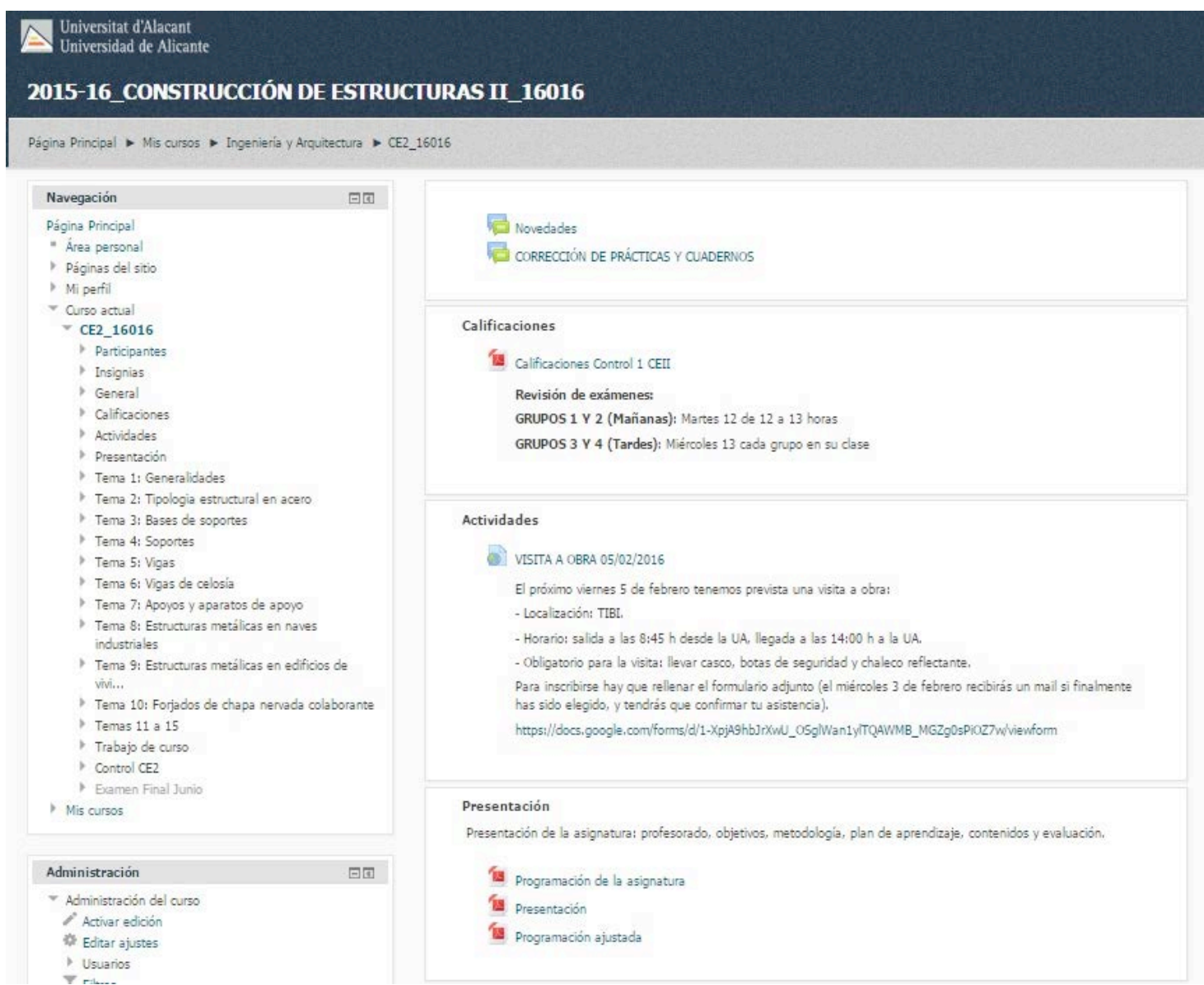

Figure 1. Main screen in the Moodle Platform.

\section{RESULTS}

\subsection{Theoretical lessons through the platform}

The two subjects of this study have developed several teaching books [8, 9, 10] with theoretical and practical content for each thematic block. In this case, and according to the schedule of the subject, the Moodle platform is used to progressively publish Power Point slides that will be projected in class (Fig. 2). This situation allows the student to view or download in advance the contents to be taught in the classroom, facilitating a more direct learning-teaching process. This procedure allows students to keep track of the class by viewing the slides projected on their own electronic devices. 


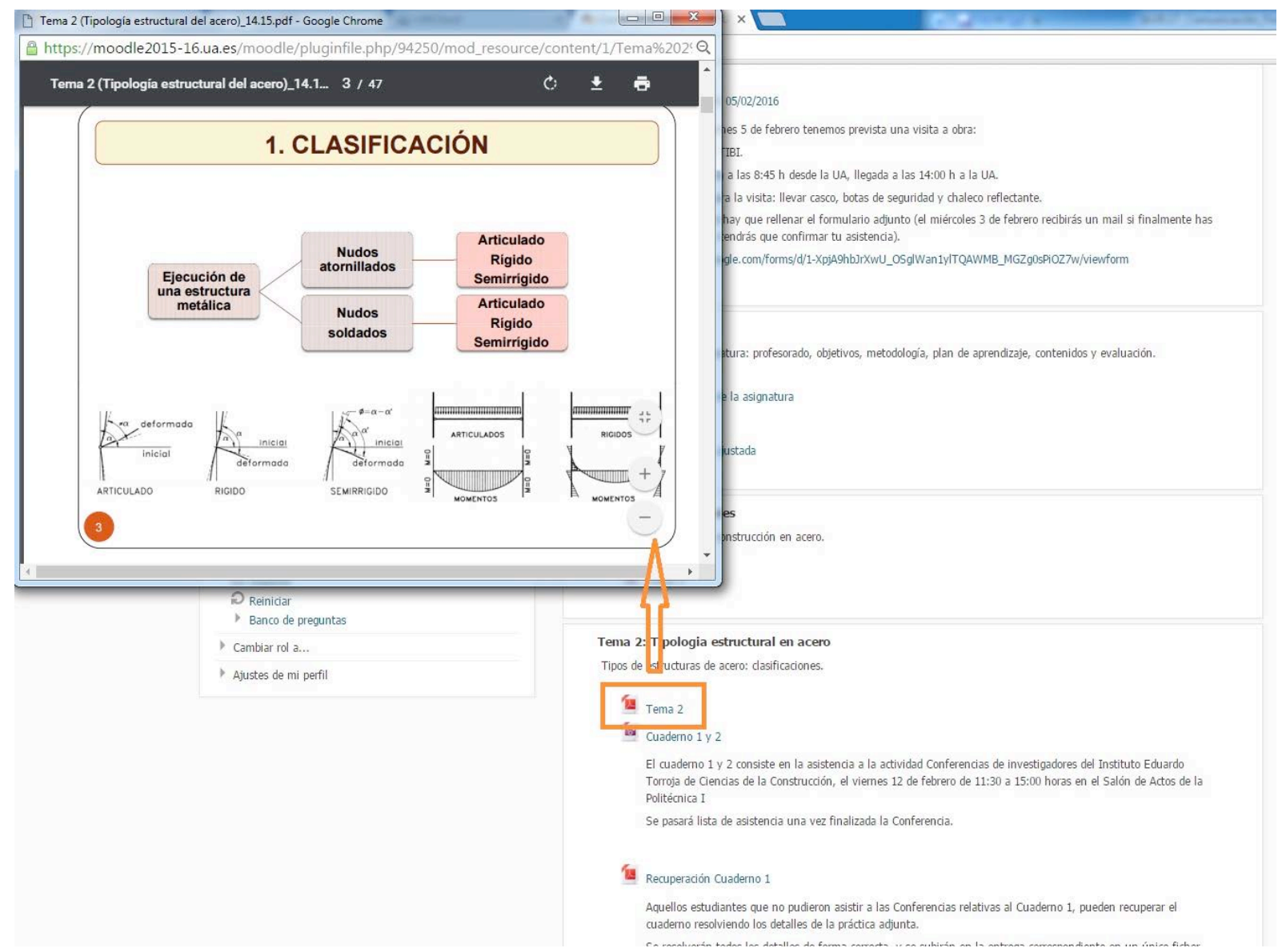

Figure 2. Teaching material available in the Moodle platform.

On the one hand, in the subject Construction of Structures I (75 enrolled students) almost all students have viewed or downloaded the materials corresponding to theoretical classes of blocks 1 to 15 during the academic course (Fig. 3); it is seen some decline in the views from block 5 and a later recover in the final part of the course. This decrease of downloads in the intermediate part of the year (blocks 5 to 10) coincides between the completion of the two exams, so it is supposed that some students decide not to fully follow the development of the subject after bad partial results.

On the other hand, in the subject Construction of Structures II (79 enrolled students) worse results are obtained. While in Construction of Structures I data remain more or less stable throughout the whole semester, in the subject Construction of Structures II there is a decline in the displays and downloads of theoretical topics from block 6 , coinciding with the development of the first exam of the subject. One of the possible causes of this situation is the location of the subject in the second semester because, at this stage of the academic course, students focus on certain subjects and stop completely to assist to others (Fig. 3).
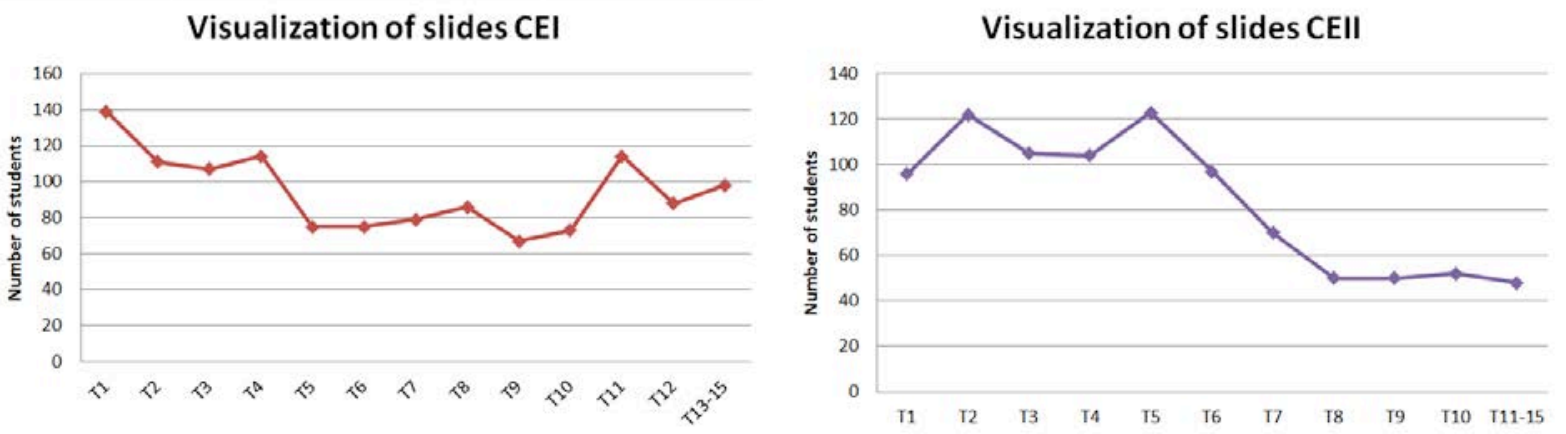

Figure 3. Viewing of slides from the Moodle platform. 


\subsection{Practical lessons through the platform}

Once the schedule for each academic year is done, necessary lectures and practical sessions are planned to achieve the objectives set on each subject. From this programming, practical statements are published prior to their implementation in class, so students can download their practice or view it with any kind of electronic device. Each practical exercise is done in groups and takes place mainly in the classroom, despite the deadline set in Moodle allows a later delivery. Practices delivered are corrected by each teacher also through the platform, writing specific comments and uploading the revised file with the final qualifications online (Fig.3).

Students can see in Moodle every correction at any time and they can download all the proper material provided since all the information is available at the platform both for the student and for the teacher (the searching process of specific documentation is easy at any place and time).

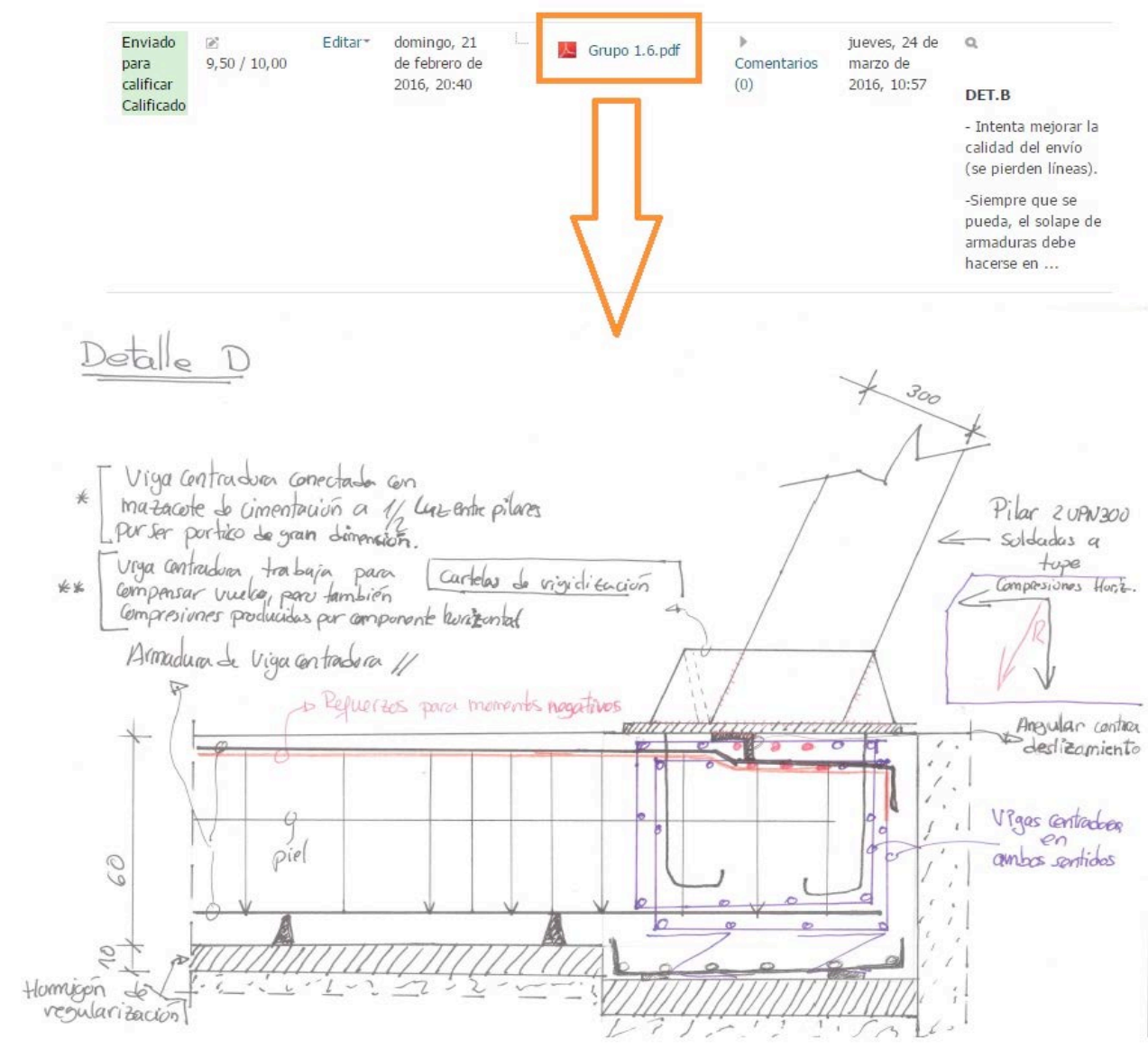

Figure 3. Student's delivery and teacher's revision of practices in the Moodle platform.

In addition to the face to face correction planned in the programming for each subject, a new forum is generated in the Moodle platform at the beginning of each exercise. This tool involves all enrolled students and all teachers and it is a common place to show any kind of doubt in the development of each exercise, as teachers can resolve the questions in real time.

Finally, it should be noted that the documentation generated in practical classes it is also uploaded to the platform (projected images in power point or blackboard drawings made in the classroom) (Fig. 4). The advantage of solving questions through this kind of forums is that all students and teachers are involved in the questions raised, and everyone feeds back from them. 


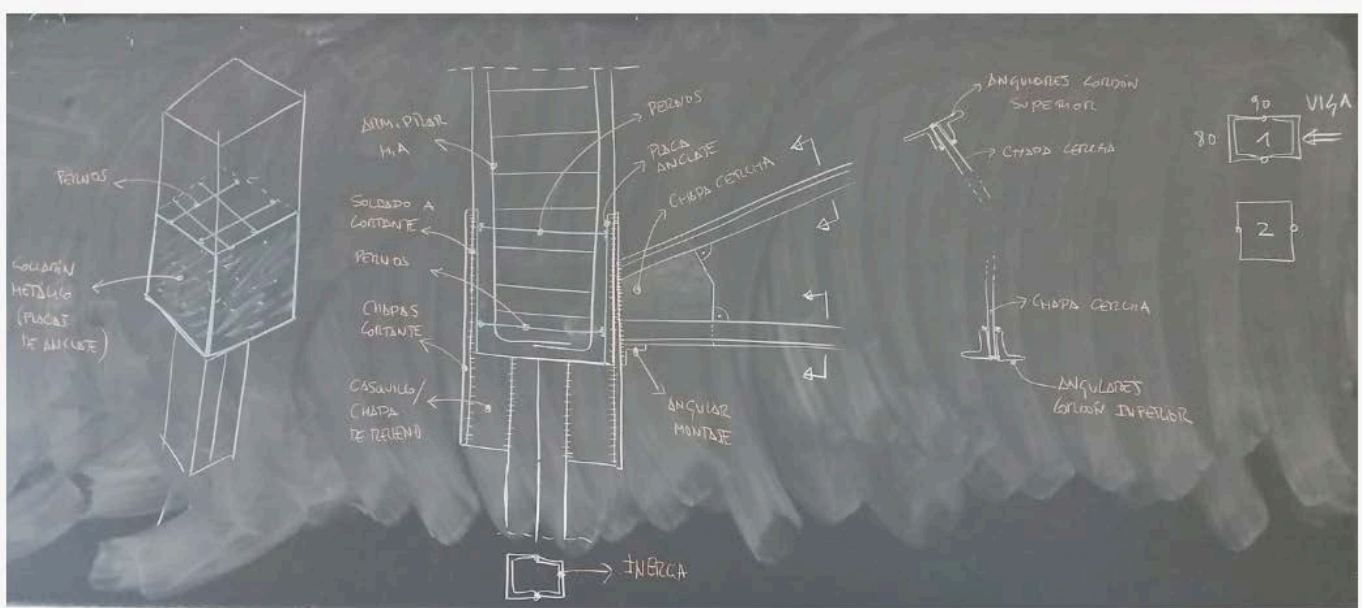

Mostrar mensaje anterior | Editar | Dividir | Borrar | Responder

Figure 4. Resolution of practices through Moodle forums.

The participation of students in the Forums can be divided into two blocks: on the one hand, students who have displayed forums about practices and on the other, those who have been actively involved with messages. The results obtained show that, in the case of Construction of Structures I (CEI), students have displayed 2746 times the correction forums but they have only written personal messages in 83 times (Fig. 6).

In the case of Construction of Structures II (CEII), a decrease is shown in the number of views (in this case forums have been viewed 1031 times) and there have only been 55 direct written messages in these forums. As mentioned, this subject belongs to the second semester and this may be a factor that affects directly or indirectly in the decrease of the students' participation in the forums (Fig. 6).

\section{Participation in Forums CEI}

- Views Messages

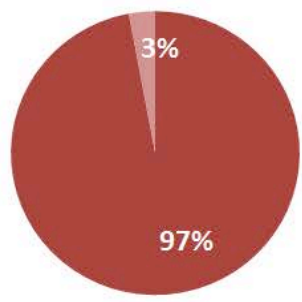

\section{Participation in Forums CEII}

aiews $=$ Messages

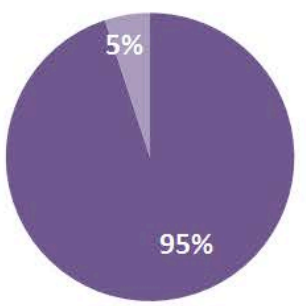

Figure 6. Participation in Forums in the subjects of CEI and CEII.

\section{CONCLUSIONS}

After the use of this platform in the subjects Construction of Structures I and II, it has been found that the various tools provided by Moodle are flexible and easily adapted to the needs of the contents taught in Degree in Building Engineering, and they can be configured or programmed with different parameters that make a powerful and easy tool to use by every academic user.

Moreover, the availability of the material uploaded to the platform, both for the students and the teachers, is searchable and editable, allowing the archive of all the generated documentation during the academic year and facilitating the consultation of such technical information. 
At a statistical level regarding the use of the platform, the results indicate that the display of material gets a great interest in both subjects $(97 \%$ and $95 \%$ respectively) while writing messages is low among participants in both cases (3\% and $5 \%$ respectively) (Fig. 6). Thus, it is concluded that it is necessary to encourage students to a more active participation in these forums. One of the possibilities to improve participation in correction practices (more written messages) for subsequent courses is to value the active monitoring in the forums so that it can affect the student's final grade (doing the same than in other activities such notebooks or visits to works).

Finally, considering the application of the methodology proposed for the 2015-2016 course, it has been shown how the resolution of practices through forums can resolve the doubts of all students with the active participation of teachers, so that all participants can feed the process solving their own / others doubts and allowing to collect the most common questions in order to be fixed in the theory classes.

\section{REFERENCES}

[1] Castell, V.; Farré, B.; Regalado, F. (2004). Biblioteca de detalles constructivos forjados inclinados: estructuras de cubierta y forjados inclinados de hormigón armado para edificación. Alicante: CYPE Ingenieros.

[2] Regalado Tesoro, F.; Farré Oro, B. (2001). Biblioteca de detalles constructivos metálicos, de hormigón y mixtos. Alicante: CYPE Ingenieros.

[3] Urban Brotons, P. (2003). Construcción de estructuras: hormigón armado: adaptado a las instrucciones EHE, EFHE y NCSE-02. Alicante: Editorial Club Universitario.

[4] Urban Brotons, P. (2003). Construcción de estructuras: hormigón armado, detalles constructivos y perspectivas. Alicante: Editorial Club Universitario.

[5] Johnson, D.W.; Johnson, R.; Smith, K.A. (2006). Active Learning: Cooperation in the Classroom. Edina: Interaction Book Company 3rd Ed., Chapter 1.

[6] Lloret Mauri,J. Diaz Santos, J.R; Jiménez Herranz, J.M. (2004). Creation and Development of an E-Learning Formative Plan. Valencia: Sefi Annual Conference.

[7] Martínez Ruiz, M. A.; Carrasco Embuena, V. (eds.) (2004). Espacios de participación en la investigación del aprendizaje universitario (I). Alcoy: Marfil.

[8] Pérez Sánchez, J.C.; Piedecausa García, B.; Mateo Vicente, J.M. (2015). Exploring CE1. Construcción de Estructuras. Alicante: Editorial Club Universitario.

[9] Pérez Sánchez, J.C.; Piedecausa García, B.; Mateo Vicente, J.M. (2015). Exploring CE2. Vol. 1. Construcción de Estructuras. Alicante: Editorial Club Universitario.

[10] Pérez Sánchez, J.C.; Piedecausa García, B.; Mateo Vicente, J.M.; Palma Sellés, P. (2015). Exploring CE2. Vol. 1. Construcción de Estructuras. Alicante: Editorial Club Universitario. 